\title{
New public management and information communication technology: Organisational influences on frontline child protection practice
}

\author{
Mike Webster ${ }^{1}$ and David McNabb ${ }^{2}$
}

\begin{abstract}
In this paper the authors examine the new public management (NPM) philosophy influencing the organisational environment in which child protection social workers are located. NPM prioritises outputs through policies, such as results based accountability (RBA) predicated on the expectation that responsibility to achieve designated programme outcomes is sheeted to the agency and its workers. Ongoing funding depends on programme results.

NPM ideology assumes that workers and managers in agencies tasked with delivering care and protection services are able to control the variables influencing outputs which contribute to outcomes. The authors will analyse four key aspects of NPM thinking (RBA, outputs, outcomes and key performance indicators) and explore their organisational consequences. The influence on social work practice of information and communications technology (ICT), on which NPM depends, is also considered.

The paper is not an ideologically based rejection of NPM, but rather an assessment of its consequences for care and protection practice. The authors call for a return to the centrality of relationally based social work processes embodied in common factors (CF) practice, such as the therapeutic alliance. We argue that CF approaches offer a contrasting and more appropriate practice philosophy than NPM thinking while still enabling achievable, multifaceted organisational benefits.
\end{abstract}

KEYWORDS: new public management; care and protection; common factors; ICT
1 University of Auckland, New Zealand

2 UNITEC Institute of Technology, New Zealand

\section{Introduction}

This paper examines the organisational environment in which child protection social workers deliver services to vulnerable populations, with a particular focus on new public management (NPM) (Hood, 1991) philosophy and consequent practice realities. The authors analyse four key aspects of NPM thinking: results based accountability ${ }^{\mathrm{TM}}$ (RBA) (Friedman, 2009), outputs, outcomes and key performance indicators (KPIs). Using their underpinning values and assumptions, we explore their organisational consequences.

Coincident with the NPM revolution (Boston, Martin, Pallot, \& Walsh, 1996), the advent of read information and communications technology (ICT) exercised a profound influence on day-to-day frontline and management work. NPM depends on data capture to measure outputs (Webster, 2013). In the Australian context, Burton and van den Broek (2009) suggest that gathering of ICT-based output data has marginalised
AOTEAROA NEW ZEALAND SOCIAL WORK 28(2), 51-63.

CORRESPONDENCE TO: Mike Wester m.webster@auckland.ac.nz 
social work ideals in favour of managerial accountabilities. Webster (2014) notes that reporting statistics has:

Invaded social work moving the emphasis on process accountability-how practitioners interact with clients-to accountability for results: a quantitative approach (Boston et al., 1996, p. 26). Such results-oriented managerial leadership may manifest itself on "checking data on computer monitors at the cost of maintaining social capital with practitioners." (Webster, 2014, p. 89)

We argue that NPM and ICT form a feedback loop which exerts significant influence on the day-to-day activities of a child protection social worker.

The authors also propose that the profession needs to reclaim the heart of practice located in empowering worker-client relationships: in other words, assign as much value to the process of service delivery as to results of intervention. We suggest that the key issue is not confined to theoretical practice models, but pays equal attention to the common factors (CF) through which those practice models are applied. Gambrill (2015) cites Lambert and Barley $(2002$, pp. 17, 18) in describing CF as "empathy, warmth, acceptance, encouragement of risk taking, client and therapist characteristics, confidentiality of the client-therapist relationship, the therapeutic alliance or process factors" (Gambrill, 2015, p. 518). Laska, Gurman, and Wampold (2014) extend this description by setting out CF as predicated on five elements necessary for change. Adapted for a social work practice context, these are: (i) an empathetic bond between worker and client; (ii) provision of confidentiality in sphere casework occurs; (iii) the ability of a worker to provide an explanation for emotional distress; (iv) the provision of practical and realistic options to address specific difficulties; and (v) the application of processes between worker and client enabling solutions. Laska et al. (2014) see the CF approach as a focus on improving practice outcomes and worker competence (p. 469). These components are appropriately summarised as Biestek's (1957) classic casework relationship, and carry conceptual links with Carl Rogers' (2004) client-centred therapy, characterised by empathy between worker and client.

The authors will explore CF values as a positive alternative to the NPM-inspired focus on data gathering while, at the same time, acknowledging the profession's accountability to the taxpayer as funder of social work programmes. We propose that the characteristic systems, or ecological thinking, of social work are well fitted to address the balancing act of competing priorities: polarities to manage rather than problems to solve (Johnson, 1992).

The paper is not an ideologically based rejection of NPM but rather an assessment of its consequences for practice. These consequences will be analysed by using Schein's (2010) cultural diagnostic approach. The purpose here is to introduce a degree of realism into political and public expectations of social workers in the highly sensitive area of child and family practice and its associated risks.

\section{Structure of the paper}

Schein (2010) proposes three levels of culture. Each level informs the next. At the base level, basic underlying assumptions, or worldview, set out the "unconscious, taken-for-granted beliefs and values which determine behaviour, perception, thought, and feeling"' (Schein, 2010, p. 24). The second level, "espoused beliefs and values" are "ideals, goals, values, aspirations; ideologies; rationalisations which may or may not be congruent with behaviour and other artefacts" (Schein, 2010, p. 24). Schein's artefacts sit at the top level of his schema. These are "visible and feelable structures and processes; observed behaviour [which are] difficult to decipher" (2010, p. 24).

Schein's cultural analysis tool informs the two opening sections of this paper. 
The sources, worldview, values and artefacts of NPM are explained in the first section. The influence exerted by NPM on social work practice and organisational leadership is examined in the second section. These implications will be addressed in the third section through the four selected components of NPM thinking (RBA ${ }^{\mathrm{TM}}$, outputs, outcomes and KPIs).

A final section will set out an alternative vision for frontline practice based on common factors theory. We call for a return to the centrality of relationally based social work processes. The authors suggest that NPM can, in fact, contribute to this alternative vision. We also draw on the International Federation of Social Workers' (IFSW) (Agius \& Jones, 2012) policy statement addressing the responsibilities of employers of social workers to provide effective and ethical working environments. The purpose of this last section is to constructively round off the article. New public management is not going away and its focus on accountabilities may work to advance commitment to stakeholders, including staff.

\section{NPM: Worldview, values and artefacts}

Pollitt (1990) argues that NPM's theoretical informant is the century-old scientific management model advocated by Frederick Winslow Taylor (Taylor, 1967). Taylor encouraged rational thinking about work organisation by advocating job analysis and improvement; the notion that there is one best way to do every job based on time and motion studies; the need for systematic selection and progressive development of each worker; and the idea of work specialisation. Apart from the one-bestway argument, these ideas remain current, illustrating the force of Taylor's thinking.

Christopher Hood (1991), credited with coining the term new public management, sees NPM thinking as one of several megatrends which emerged simultaneously. Others included neoliberal attempts to limit or reduce public spending and state-sector staffing levels; the move towards full or partial privatisation (the provision of services by organisations outside the public sector); and ICT automation in service provision (Hood, 1991, p. 3).

Hood's megatrends are reflected in the definitive study of the New Zealand public sector management revolution by Boston et al. (1996). Boston and his colleagues suggest that, in its broadest terms, NPM proposes that private sector management should be applied to the public sector by focusing on accountability for results rather than process. Management responsibility is devolved; emphasis is placed on management information systems for monitoring purposes. Contracting out services to the private sector, or in the case of social work services, to not-for-profit organisations, is preferred in pursuit of the notion that policy advice and service provision should be separate functions-the "funder-provider" split (Chapman \& Duncan, 2007, p. 2).

Contracts are characterised by specificity.

Visible changes-artefacts-emerging from these approaches included private sector management practices such as employment contracts, strategic plans and mission statements, performance-related pay, KPIs for the organisation and its staff, and a concern for corporate image. Incentives were financial rather than ethical; cost-cutting in the guise of efficiency became a prime management focus.

Boston et al. (1996, p. 6) capture these changes in public sector management in their description of "the remarkable transformation of public management in New Zealand." This transformation was characterised by a new language of discourse. Administration was replaced by management- performance management, management of risk, and so on. Competitive tendering for service provision, principal-agent contracting and purchase agreements, customers, stakeholders, KPIs for organisational and managerial performance all made their 
appearance. This terminology created a seismic cultural shift for social workers, their managers and leaders (Heffernan, 2006).

The implications of NPM ideology vis-à-vis social work service delivery and organisational leadership have been extensively addressed in social work literature in the UK, Australia, Sweden and Aotearoa New Zealand (see, for example, Carey, 2009; Coffey, Dugdill, \& Tattersall, 2009; Fitzgibbon, 2008; Höjer \& Forkby, 2011; Webster, 2013). Carey (2009, p. 569) addresses "Taylorist managerial control," a reference to the deskilling of workers by placing work planning in management hands.

Carey's (2007) perceptive analysis of Taylorism applies Braverman's (1974) Marxist analysis of work (Labor and Monopoly (apital) to organisationally based social work practice. Carey portrays Braverman's thesis as depicting control of labour by management, whereby the worker's knowledge and skills are subordinated to the employing organisation through the device of mechanistic, routine tasks: a perspective which effectively summarises the critique of Taylorism. Carey argues however, that the advent of the knowledge organisation may run counter to Braverman's "perpetual workplace deskilling assumption" (Carey, 2007, p. 108). On the other hand, Carey observes that competency-based social work education and workplace training minimises the acquisition of critical theory and thus deskills workers through loss of professional autonomy. Carey also suggests that ICT data-entry obligations placed on workers reinforces Braverman's argument that the brain of the manager is separated from the hand of the worker who has no input into template design. Taylor's principle that there is one best way to do every job as determined by management (Inkson \& Kolb, 2002) arguably validates Braverman's critique of management control of workers.

Drawing on Carey (2007) and Inkson and Kolb (2002), we suggest that Taylorist managerialism has tended to rob workers of their self-worth by virtue of two prime influences. The first relates to the imposition of quantitative KPIs and the one-best-way argument. These requirements arguably remove, or at least reduce, professional autonomy in applying knowledge to worker-client interactions. Second, management's capacity to design computer templates and require workers to populate them illustrates Carey's portrayal of mechanistic, routine tasks which, again, detrimentally affects social work professionalism. In the New Zealand context, social work provision must be seen through the lens of these seminal organisational changes to which NPM has contributed since the passage of the State Sector Act in 1987.

\section{New public management: Influence on social work practice and organisational leadership}

A growing literature explores the influence of NPM on social work practice and leadership. In the New Zealand context, O'Donoghue, Baskerville, and Trlin (1999) consider that the new managerialism in New Zealand public sector social service agencies resulted in a transformation of "professional practice and management" of those agencies (pp. 8, 9). This transformation was marked by management accountability for measuring outputs and performance targets replacing the former primacy of accountability for social work processes via professional supervision (O’Donoghue et al., 1999). Professionals were made accountable to managers who rationalised their market solutions approach by a need for economy, efficiency and effectiveness (Beckmann \& Cooper, 2004; Kemshall, 1995). Writing in the Australian context, Healy (2009) assesses NPM as exercising a corrosive effect on social workers' identity and influence. From this perspective, NPM's dominating economic base was seen as challenging, and even subordinating, social work's ethical commitment to such values as respect for, and trust in, clients' self-determination and equality of opportunity. 
McDonald and Chenoweth (2009) analyse social work leadership in the context of neo-liberal workfare regimes in the Anglophone welfare states. They argue that governments have driven institutional change by virtue of their control of resources, and, further, in a relevant perspective for this article, that "neo-liberalism has taken on a hegemonic status" (2009, p. 104) in welfare bureaucracies. McDonald and Chenoweth also suggest (2009, p. 105) that the notion of transformational leadership (Burns, 1978) is inimical to social work values and philosophy:

Transformative leadership inevitably happens within the context of competition and conflict. We tentatively suggest that this characteristic represents one of the core reasons why social workers exhibit ambivalence about leadership — to engage as leaders inevitably means engaging in competition and conflict, processes which are counter-intuitive to the (probably learned) dispositions of social workers. (McDonald \& Chenoweth, 2009, p. 107)

These are perceptive insights. The authors suggest that they go to the heart of the tension as perceived by social workers between the exercise of leadership or managerial power-what McDonald and Chenoweth describe as engaging in competition and conflict-and the profession's commitment to empowerment of marginalised groups. How this tension is managed will be influenced-or even determined-by the profession's culture.

Reverting to Schein's (2010) cultural diagnostic framework, the authors suggest that NPM's new discourse (Boston et al., 1996) in the organisational social work context offers insight into the profession's values. Investigations by Heffernan (2006) and McLaughlin (2009) into the significance of word usage illustrate this perspective. Writing in the UK context, Heffernan explores the term service user as preferred NPM terminology. She argues that NPM's goal "appears to be the transmogrification of public sector culture to mirror that of the private sector" (2006, p. 141). To achieve that purpose, Heffernan suggests, organisational social work practice has taken on a "quasi business" (2006, p. 141) identity by using such terminology as customer services, performance standards, cost-effectiveness, accountability.

McLaughlin (2009, p. 1101) discusses how the terms "client, customer, consumer, service user" have developed in England. In the context of the Thatcher new right government elected in 1979, whose equivalent in New Zealand was the fourth Labour government from 1984 to 1990 and its National successor, he identifies the emergence of an emphasis on economy and efficiency, the institution of market conditions and the "need to regard clients as customers" (McLaughlin, 2009, pp. 1103-1104.) McLaughlin traces how social workers became "care managers" and clients became "consumers or customers." In relation to this paper, he makes a crucial observation:
"Consumers" signify a relationship in which welfare is seen as a product for the consumer, managed by a case or care manager who is accountable to the state and their manager much more so than to their profession or those using the service. "Customers", on the other hand, signified a marketization of social care wherein welfare was a commodity for the customer. The worker became more of a broker, accountable to management. (McLaughlin, 2009, p. 1104)

The analyses offered by Heffernan (2006) and McLaughlin (2009) provide useful starting points for considering the significance of language as an observable artefact in order to assess the culture in which social work practice occurs and organisational leadership is exercised. Four commonly used NPM terms (RBA ${ }^{\mathrm{TM}}$, outputs, outcomes and KPIs) listed in Table 1 have been selected for further analysis. 
Table 1. Words as Artefacts: Their Potential Meanings in Social Work Organisations

\begin{tabular}{|l|l|l|l|}
\hline $\begin{array}{l}\text { NPM term (alphabetically } \\
\text { ordered) }\end{array}$ & Values, beliefs & Assumptions/Worldview & $\begin{array}{l}\text { Inferential meaning for } \\
\text { organisations and their workers }\end{array}$ \\
\hline $\begin{array}{l}\text { Accountability for results } \\
\left.\text { (RBA }{ }^{T}\right)\end{array}$ & $\begin{array}{l}\text { Responsibility to achieve } \\
\text { designated purpose of social } \\
\text { work services is important }\end{array}$ & $\begin{array}{l}\text { Organisation and its workers } \\
\text { deemed responsible for client } \\
\text { buy-in to programme's purpose } \\
\text { as the criterion for its continuation }\end{array}$ & $\begin{array}{l}\text { Ongoing funding for workers and } \\
\text { organisations is dependent on } \\
\text { programme results }\end{array}$ \\
\hline $\begin{array}{l}\text { Key performance indicators } \\
\text { (KPIs) }\end{array}$ & $\begin{array}{l}\text { Workers and managers are } \\
\text { able to control most or all the } \\
\text { variables that contribute to } \\
\text { outputs }\end{array}$ & $\begin{array}{l}\text { An organisation consists of } \\
\text { outputs over which workers and } \\
\text { managers exercise significant } \\
\text { power }\end{array}$ & $\begin{array}{l}\text { Remuneration and career prospects } \\
\text { are dependent on achieving KPIs }\end{array}$ \\
\hline Outcomes & $\begin{array}{l}\text { Social work organisation } \\
\text { outputs are a prime factor } \\
\text { in achieving government- } \\
\text { mandated societal outcomes }\end{array}$ & $\begin{array}{l}\text { Professionals (social workers in } \\
\text { this instance) are responsible for } \\
\text { individual client decisions which } \\
\text { contribute to desired outcomes }\end{array}$ & $\begin{array}{l}\text { Achieving generic outcomes as } \\
\text { determined by government is a } \\
\text { constant expectation }\end{array}$ \\
\hline Outputs & Numbers are vital & $\begin{array}{l}\text { Funders value numerical as much } \\
\text { as qualitative measurements }\end{array}$ & $\begin{array}{l}\text { Workers and managers must achieve } \\
\text { numerically as much as qualitatively }\end{array}$ \\
\hline
\end{tabular}

\section{Discussion: The implications of NPM for social work organisational practice}

Recognising that NPM is now embedded in the public sector including social work agencies (Webster, 2013), a critical analysis addressing current realities is proposed. We treat the four terms as distinctive elements of an integrated whole (Figure 1). Each element must be understood to comprehend the whole.

\section{Results-based accountability, outputs, outcomes and KPIs as a "building block"}

Scott (2001, p. 11) describes performance management and accountability as one of seven building blocks which were pivotal in the post-1987 transformation of the policies, practice and culture of government departments including social work agencies such as Child Youth and Family (CYF). Their adoption resulted in the replacement of an input budgeting approach by public sector social service entities by output and outcome expectations by government. Inputs, which include salaries and wages, refer to the resources used to produce outputs. Outputs are measurable and include policy advice, administration of statutes, regulations and delivery of services such as social work services to children. "Outcomes" represent government-mandated results in society of outputs produced, e.g., for CYF care and protection services, "[v]ulnerable children are protected from abuse and neglect; children and young people are in safe and permanent care" (Ministry of Social Development (MSD), 2014). The reforms enabled government to choose preferred outcomes, set policy priorities to achieve those outcomes, and select suitable outputs (Boston et al., 1996, pp. 263-264).

Within the larger context depicted in Scott's (2001) accountability building block, RBA $^{\mathrm{TM}}$ (Friedman, 2009) is presented as "ultimately about two questions: Population Accountability: 'How do we improve the lives of the people in our community?' and Performance Accountability: 'How do we improve the performance of our programmes?'“ (MSD, n.d., p. 8.) We suggest that the quantitative element (programme performance) stands at the heart of social work's apprehensions expressed earlier 


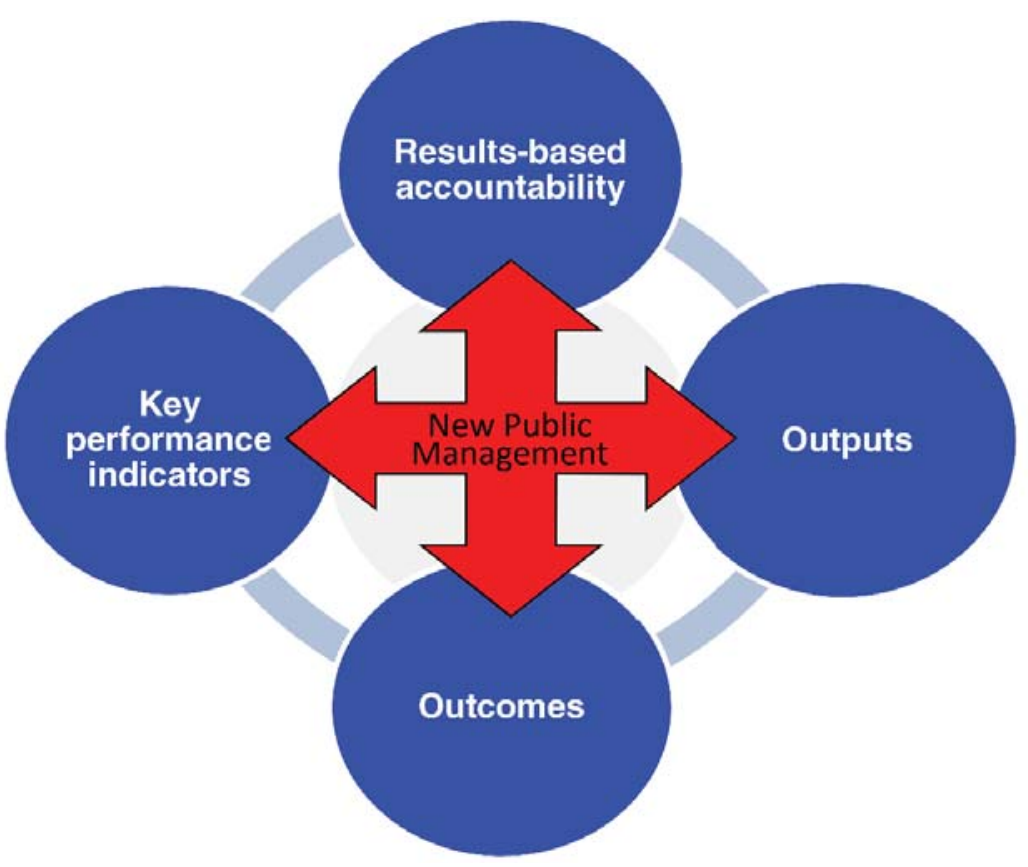

Figure 1. New Public Management Interrelationships: Results-Based Accountability, Outputs, Outcomes and Key Performance Indicators

regarding statistical reporting which moves the emphasis on process accountabilityhow practitioners interact with clients-to accountability for results: a quantitative approach (Burton \& Van den Broek, 2009; Webster, 2014). Pinnock (2012) perceptively addresses this suspicion:

Over the past 15 years I've seen the simple idea of evaluating outcomes in social care recklessly damaged by its association with the arrogant excesses of so-called "performance management". For many, the very idea of measuring progress has become a tyranny. Each week the media brings us yet another example of some cynical management contrivance for creating the impression of "improved performance". But just like the little trick of recording [an] aborted visit to the clinic as "Did not attend", it often creates an unreliable impression of the service it purports to represent. (Pinnock, 2012, p. 23)

The tyranny noted by Pinnock is located in the contractual model inaugurated by the NPM revolution: Boston's (1995) "state under contract." From the chief executive's negotiated agreement with the Minister down to a social worker's performance agreement with his or her frontline manager, responsibility for expected outputsintended to contribute to societal outcomes via the contract model-may permeate an agency. Annual performance planning and reviews (Rudman, 2010) are the mechanisms by which this accountability is exercised and become the new organisational culture for practitioners.

KPIs are the sharp end of the four terms being considered, defined by Parmenter (2010, p. 4) as "a set of measures focusing on those aspects of organisational performance that are the most critical for the current and future success of the organisation." Parmenter suggests that, to be effective, KPIs must: be frequently measured (not less than once a week); be acted on by senior management; unambiguously set out required actions by individual staff and teams; impact on critical success 
factors and encourage appropriate action (Parmenter, 2010, p. 6). The authors of this paper see KPIs as the cutting edge by which the MSD's performance accountability is assessed. While KPIs offer clarity on required staff action, they also carry potential for micromanagement. Senior managers may hold frontline workers to account for system-based problems of greater complexity than individuals, teams or even organisations can realistically control. As noted in Table 1, the insatiable demand for data may also create the impression that numbers are valued as much as qualitative measurements. In examining child protection social work practice in England, Munro (2010, p. 1135) identifies these factors as constituting a culture "in which professional practice is being excessively controlled and proceduralised [as evidenced by] the blame culture and the performance management system." Munro also suggests that these factors detract from opportunities to learn.

The authors suggest that the cynicism with which social workers may treat statistical reporting on KPIs, outputs and even outcomes, emanates from their inherent quantitative bias. In addition, Scott (2001, p. 196) points out that "achieving outcome goals is not easy." He suggests that "outcomes are typically the result of a wide range of factors that are only partially within the control of a chief executive" (Scott, 2001, p. 175). CYF's statement of intent (MSD, 2014, p. 10) that "vulnerable children are protected from abuse and neglect; children and young people are in safe and permanent care" illustrates Scott's realism, obligating an honest examination of its achievability. If espoused goals are interpreted as inevitably failing to meet the test of "specific, measurable, achievable, realistic and time-based [SMART]" goals (Lawler \& Bilson, 2010, p. 84), cynical reactions may result. Alternatively, such objectives may be interpreted as aspirational, suggesting potential incompatibility with NPM's orientation towards accountability for results by the organisation.
Although RBA ${ }^{\mathrm{TM}}$ has been adopted by the MSD (MSD, n.d.) Pinnock (2012) offers an affirmative, practitioner's take on RBA $^{\mathrm{TM}}$ in his frontline role managing children's services in the UK. He suggests that measuring outcomes serves two objectives: the purpose of external accountability and an internal purpose of organisational learning (Pinnock, 2012, p. 24). Pinnock sets out seven Cs of outcomes:

- Clear - they're easily understood by both professional and lay audiences

- Child-centred - they're about children's lives - not management's "mission"

- Concise - they give us a memorable and portable vision of a desired future

- Consensual - they describe a shared purpose that everyone can sign up to

- Constant - they remain constant over time and place

- Comprehensive - they encourage us to see the "whole child"

- Challenging - they're inspirational as well as aspirational (Pinnock, 2012, p. 24).

Pinnock's outcomes read as qualitative rather than quantitative statements. $\mathrm{He}$ proposes that clear outcomes are a "work in progress" (2012, p. 24)—a striking phrase carrying distinct affinity with the process noted earlier of how practitioners interact with clients. Pinnock (2012) argues that childcentred outcomes enable social workers to reconnect with their vocation and thus gain "meaning and authenticity" (p. 25) by virtue of the commitment to those outcomes for the child. Concisely worded outcomes allow better recall, the opposite of "wordy, jargonladen statements of purpose" (Pinnock, 2012, p. 25) characteristic of management discourse. The notion of consensual, shared-purpose outcomes expresses the collegiality of the profession and the need for partnership between practitioners and the families in children's social work practice (Turnell \& Edwards, 1997). Pinnock (2012) observes that "effective partnerships give a community a massive advantage [and that] trusting relationships are usually the place where innovative work begins" (p. 27). He further 
suggests that a commitment to constant outcomes transcends changes caused by "political party, funding levels, boundary changes, management-fad, and organisational structure" (Pinnock, 2012, p. 25).

Pinnock offers a summative declaration that "outcome statements should leave us with a powerful and challenging mental image of the world that we're working to create with children and young people" (2012, p. 26). This statement provides a sense of purpose for organisational learning (Munro, 2010) equivalent to Senge's (1997) influential notions of mental models and shared vision. Pinnock suggests that to realise those core disciplines effective leadership is required (2012, p. 26). These elements form part of the final section of this paper, which presents the authors' vision for best social work practice in the context of management informed by NPM.

\section{Best practice}

To provide this vision, we argue that the interactions between social workers and the populations they serve stand at the heart of professional practice, and should be prioritised. We also suggest that time taken for quantitative data gathering required by NPM-mandated output measurements has detracted from the application of core skills and ethically based behaviours directly related to working with vulnerable and marginalised populations.

The efficacy of research-based practice approaches is the subject of an extensive literature, too wide for detailed analysis in this article. However, dialogue with a practice colleague in CYF (Dave Wood, personal communication, 2015) suggests that, for the purpose of this paper, the current interest in common factors theory (CF) is appropriately selected to illustrate Gambrill's (2015) useful examination of "ethical, evidence-informed interventions to clients" (p. 510). As outlined earlier, CF is a practice approach which offers demonstrably positive outcomes for clients.
CF may be regarded as the ethically based attitudes and behaviours of social work practitioners which inform and add value to their practice models. CF is conceptually similar to strengths-based practice (Saleebey, 2006) in that the values espoused are expressed in the social worker's interactions with clients; they do not constitute a practice model. Laska et al. (2014) enumerate a complete list of CF as "[the therapeutic] alliance, empathy, goal consensus/collaboration, positive regard/ affirmation, congruence/genuineness" (p. 472). According to these authors, the therapeutic alliance consists of the bond between the worker and the client, their agreement on goals sought and tasks undertaken through the working relationship (2014, p. 471) expressing Turnell and Edwards' (1997) advocacy for a partnership between practitioners and families.

Therapeutic alliances inherent in CF approaches apply to a wide range of social work practice. In the mental health context for example, Bland, Renouf, and Tullgren (2015, p. 7) note the fundamental importance of relationships between social workers and service users and carers and, indeed, service providers. Relationships are particularly important for their healing potential. The key principles for social work practice in mental health build on the foundation of relationships: emphasising personhood; valuing the lived experience of individual consumers and family members and carers; affirming the importance of partnership and mutuality; addressing powerlessness, marginality, stigma and disadvantage; and conveying empathy, compassion and hope (Bland et al., 2015, pp. 10-11). While these social work principles are not exclusive to the mental health context they demonstrate an application of social work principles to a field linked to the CF principles of alliance, empathy and partnership.

The organisational context is particularly important for social work because our location for practice is often in the public welfare arena where we are exposed to the power of government policy and funding controls. This influence reaches 
through to the organisational setting of social work practice. The global social work profession has developed policy to address the organisational context of practice: The global social work profession has developed polity to address the organisational context of practice (Agius \& Jones, 2012). This policy asserts that the goals of ethical practice and organisational accountability can both be met, but that effective and ethical social work practice cannot be achieved without a supportive working environment that upholds these goals. In the light of our discussion on NPM and its narrow focus on organisational accountability of workers, this policy is a corrective with its corresponding emphasis on social work ethics and values.

What actions can be taken by the profession to address the challenges of NPM and ICT within statutory child protection practice? The authors propose that the core requirement is that child protection social workers must reclaim the critical relationship with families expressed in CF thinking. Because cultural values and ideas have consequences (Hofstede, 2001; Weaver, 1984) a commitment to $\mathrm{CF}$ at the heart of practice must be non-negotiable. We have no doubt that practitioners in child protection work operate from that value base. Organisational leadership is needed to prioritise CF practice over the reporting of contracted targets in the complex field of child protection. Recognition by stakeholders-particularly frontline, middle and senior managers-of the intrinsic value of the work undertaken offers a powerful workforce motivator as Herzberg (2003) saw almost 50 years ago in his now-classic article, "One more time: How do you motivate employees?" Herzberg also observed that the work in itself motivates practitioners. Social workers did not join the profession to enter data on computer templates and are unlikely to be motivated by such activity.

In Aotearoa New Zealand a hui (meeting) initiated by the Social Work Action Network (SWAN) within the Public Service
Association (PSA) (PSA, 2015) in August 2015 identified some critical factors in this field. The Workload and Case Review (Office of the Chief Social Worker, 2014) found that social workers in care and protection practice spent $25 \%$ of their working hours in contact with the people they serve (Figure 2). UK anecdotal reports suggest that social workers might spend $80 \%$ or even $90 \%$ of their time on computer tasks (British Association of Social Workers (BASW), 2012, p. 82). In response to the question, "How have cuts to back office staff impacted on your role?" one participant commented: "Being endlessly hassled to tick boxes on computers to meet targets, for no real gain to service users" (BASW, 2012, p. 79).

This hui was set in the wider context of institutional racism and the need for practice that liberates Māori from making up a majority of the children in care and under case management. The call for change found in Puao te ata tu that informed the Children Young Persons and Their Families Act 1989, still awaits fulfilment (PSA, 2015, pp. 11-12,14). The hui made a range of recommendations: address other structural problems such as inequality and poverty; resource social workers and ensure lower caseloads as stated in the Workload and Casework Review (Office of the Chief Social Worker, 2014); for a cohesive vision for CYF; that services are whānau-centred not just child-centric; that social workers are empowered in their practice; to be wary of privatising foster care and of the uncritical use of predictive risk modelling practice approaches (PSA, 2015, pp. 14-17). NPM does not address these wider challenges. The report initiated by government on CYF, (The Modernising Child Youth and Family Panel, 2015), while recommending significant investment for children in care does not address structural issues of racism and inequality, nor the professional concerns of holistic practice and social worker support.

The crucial point to make relates to the centrality of the professional relationship 


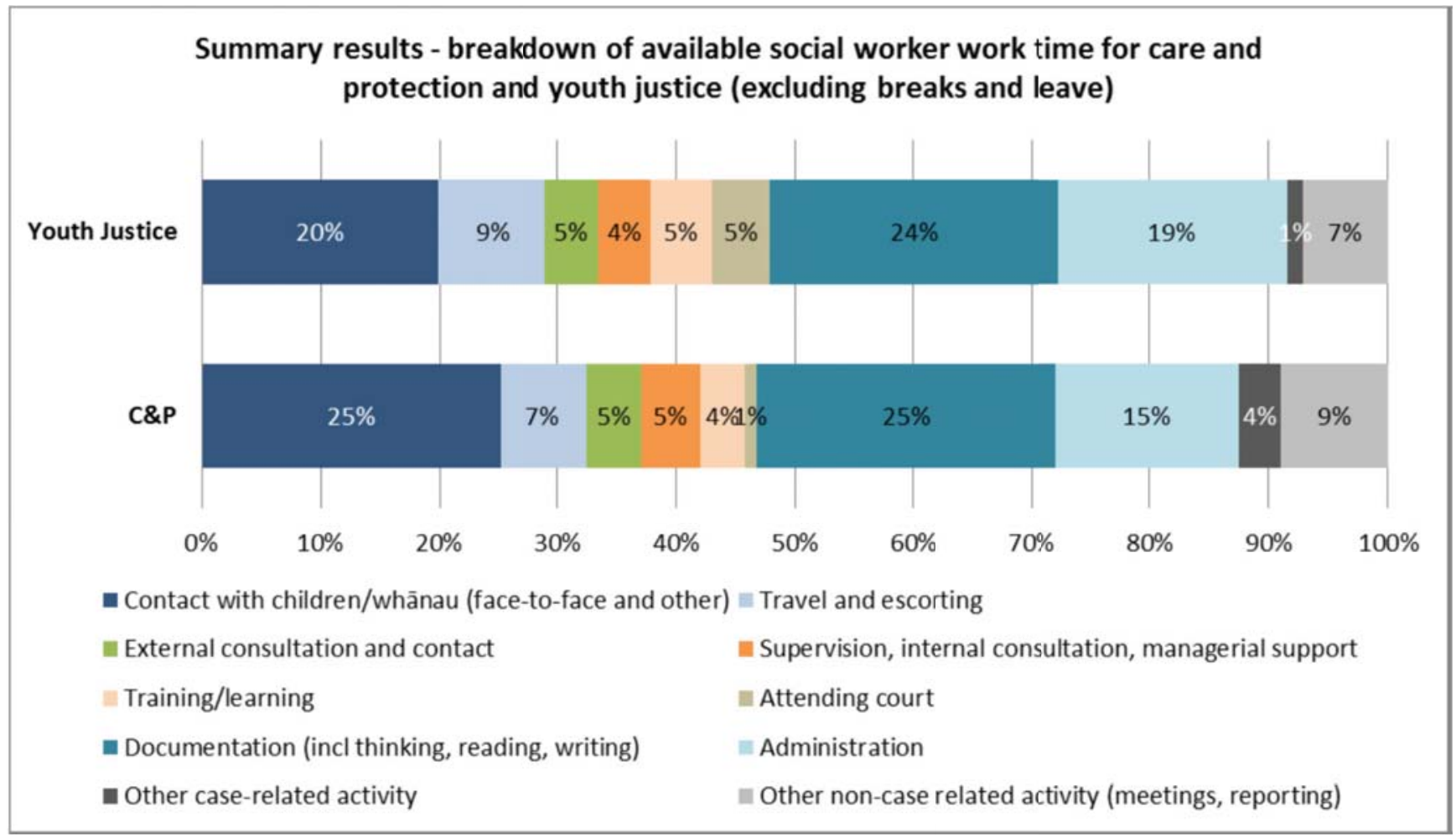

(Source: Office of the Chief Social Worker, 2014, p. 71)

Figure 2. Breakdown of Available Work Time for Care and Protection and Youth Justice Social Workers

between practitioners, children and their families. Wampold's research (see, e.g., Wampold, 2001; Wampold \& Budge, 2012) has found that up to $60 \%$ of successful treatment outcomes are attributable to the client's perception of the therapeutic alliance, or CF. Early assessments by the recipients of the trust to be placed in the worker are also critical (Babor \& Del Boca, 2003). This paper therefore proposes that, for optimal outcomes, child protection social workers must be allocated a greater proportion of their working week to client engagement, perhaps up to $50 \%$ in the early stages, defined as the first six weeks in Babor and Del Boca's (2003) study. The benefits are multifaceted. Borrowing from the BASW (2012) statement, worker motivation is likely to improve; client trust in the social worker stands a better chance of being established; and the outcomes sought by NPM organisational policies will be enhanced.

\section{Conclusion}

Social workers are not data entry operators, nor statisticians charged with recording targets. They are organisationally and professionally accountable for their knowledge and skills bases required in the processes of engaging with vulnerable families. The authors of this paper argue that, according priority to those processes can take advantage of NPM's accountability thinking. Accountabilities in this instance are funders represented by the Minister, service recipients, communities, and social work managers from frontline to senior levels. We propose that this accountability now needs to offer equal recognition to the most significant stakeholders of all: the care and protection social work workforce.

The recent SWAN/PSA hui offers a pathway to advance that recognition. Drawing 
specifically from the hui, the authors propose a threefold strategy

(A, B, and C.) Based on the development of a consensus from (i) social work educational providers; (ii) the Social Workers Registration Board; (iii) the Aotearoa New Zealand Association of Social Workers; and (iv) the MSD and, if applicable, the future Children's Ministry we suggest:

A. A policy and practice commitment to:

- The specific provisions of the United Nations Convention on the Rights of the Child (UNCROC, as ratified by New Zealand);

- The holistic family-centric approach, encompassing all ethnicities, to social work practice as set out in the hui document, UNCROC and CF practice.

B. The integration of theory and practice (as developed through strategy A) by management in MSD/Ministry for Children.

C. Government and MSD/Ministry for Children management commitment to resourcing $50 \%$ of social workers' working week in the early stages of family engagement as suggested in the research cited above.

We believe that these strategies address causative factors thus replacing reactive modes of thinking and practice.

\section{References}

Agius, A., \& Jones, D. N. (2012). Effective and ethical working environments for social work: The responsibilities of employers of social workers. Berne, Switzerland: International Federation of Social Workers.

Babor, T., \& Del Boca, F. K. (2003). Treatment matching in alcoholism. Cambridge, England; New York, NY: Cambridge University Press.

Beckmann, A., \& Cooper, C. (2004). "Globalisation", the new managerialism and education: Rethinking the purpose of education in Britain. Journal for Critical Education Policy Studies, 2(2).

Biestek, F. P. (1957). The casework relationship. Chicago, III.: Loyola University Press.
Bland, R., Renouf, N., \& Tullgren, A. (2015). Social work practice in mental health: An introduction (2nd ed.). Crows Nest, NSW: Allen \& Unwin.

Boston, J. (Ed.). (1995). The state under contract. Wellington, NZ: Bridget Williams Books.

Boston, J., Martin, J., Pallot, J., \& Walsh, P. (1996). Public management: The New Zealand model. Auckland, NZ: Oxford University Press.

British Association of Social Workers. (2012). Voices from the frontline: The state of social work 2012. Birmingham, England: Author.

Burns, J. M. (1978). Leadership. New York: Harper and Row.

Burton, J., \& Van den Broek, D. (2009). Accountable and countable: Information management systems and the bureaucratization of social work. British Journal of Social Work, 39(7), 1326-1342. doi:10.1093/bjsw/bcn027

Carey, M. (2009). The order of chaos: Exploring agency care managers' construction of social order within fragmented worlds of state social work. British Journal of Social Work, 39(3), 556-573. doi:10.1093/bjsw/bcm 143

Chapman, J., \& Duncan, G. (2007). Is there now a new "New Zealand model"? Public Management Review, 9(1), 1-25.

Coffey, M., Dugdill, L., \& Tattersall, A. (2009). Working in the public sector: A case study of social services. Journal of Social Work, 9(4), 420-442. doi:10.1177/1468017309342177

Fitzgibbon, D. W. (2008). Deconstructing probation: Risk and developments in practice. Journal of Social Work Practice, 22(1), 85-101.

Friedman, M. (2009). Trying hard is not good enough: How to produce measurable improvements for customers and communities. Charleston, SC: BookSurge.

Gambrill, E. (2015). Integrating research and practice: Distractions, controversies, and options for moving forward. Research on Social Work Practice, 25(4), 510-522. doi:10.1177/1049731514544327

Healy, K. (2009). A case of mistaken identity: The social welfare professions and New Public Management. Journal of Sociology, 45(4), 401-418. doi 10.1177/ 1440783309346476

Heffernan, K. (2006). Social work, new public management and the language of 'service user'. British Journal of Social Work, 36(1), 139-147. doi 10.1093/bjsw/bch328

Herzberg, F. (2003). One more time: How do you motivate employees? Harvard Business Review, 81(1), 87-96.

Hofstede, G. (2001). Culture's consequences: Comparing values, behaviors, institutions, and organizations across nations (2nd ed.). Thousand Oaks, CA: Sage.

Höjer, S., \& Forkby, T. (2011). Care for sale: The influence of new public management in child protection in Sweden. British Journal of Social Work, 41(1), 93-110. doi 10.1093/bjsw/bcq053

Hood, C. (1991). A public management for all seasons? Public Administration, 69(1), 3-19.

Inkson, K., \& Kolb, D. (2002). Management: Perspectives for New Zealand (3rd ed.). Auckland, NZ: Pearson Education.

Johnson, B. (1992). Polarity management: Identifying and managing unsolvable problems. Amherst, MA: HRD Press. 
Kemshall, H. (1995). Supervision and appraisal in the probation service. In J. Pritchard (Ed.), Good practice in supervision (pp. 139-152). London, England: Jessica Kingsley.

Lambert, M. J., \& Barley, D. E. (2002). Research summary on the therapeutic relationship and psychotherapy outcome. In J. C. Norcross (Ed.), Psychotherapy relationships that work: Therapists' contributions and responsiveness to patients (pp. 17-32). New York, NY: Oxford.

Laska, K. M., Gurman, A. S., \& Wampold, B. E. (2014). Expanding the lens of evidence-based practice in psychotherapy: A common factors perspective. Psychotherapy: Theory, Research, Practice, Training, 51(4), 467-481.

Lawler, J., \& Bilson, A. (2010). Rational planning and control. In Social work management and leadership: Managing complexity with creativity (pp. 75-100). London, England: Routledge.

McDonald, C., \& Chenoweth, L. (2009). Leadership: A crucial ingredient in unstable times. Social Work \& Society, $7(1), 102-112$.

McLaughlin, H. (2009). What's in a name: "Client", "patient", "customer", "consumer", "expert by experience", "service user"-what's next? British Journal of Social Work, 39(6), 1101-1117. doi 10.1093/bjsw/bcm155

Ministry of Social Development. (2014). Statement of intent 2014-2018. Wellington, New Zealand: Author.

Ministry of Social Development. (n.d.). Results based accountability ${ }^{T M}$ : Guidelines and resources. Wellington, NZ: Author.

Munro, E. (2010). Learning to reduce risk in child protection. British Journal of Social Work, 40(4), 1135-1151. doi 10.1093/bjsw/bcq024

O’Donoghue, K., Baskerville, M., \& Trlin, A. D. (1999). Professional supervision in the new managerial climate of the Department of Corrections. Social Work Review, 11(1), 8-15.

Office of the Chief Social Worker. (2014). Workload and casework review: Qualitative review of social worker caseload, casework and workload management. Wellington, NZ: Author. Retrieved from http://www.msd. govt.nz/about-msd-and-our-work/newsroom/mediareleases/2014/statement-from-brendan-boyle-chiefexecutive.html

Parmenter, D. (2010). Key performance indicators (KPI): Developing, implementing, and using winning KPls (2nd ed.). Hoboken, NJ: Wiley.

Pinnock, M. (2012). How outcomes saved my life (or at least my sanity). Social Work Now, 51, 22-28.

Pollitt, C. (1990). Managerialism and the public services: The Anglo-American experience. Oxford, England: Basil Blackwell.

Public Service Association. (2015). CYF review: Let's get real. Retrieved from http://www.psa.org.nz/assets/PDFs/ PSA-CYF-review-2015.pdf

Rogers, C. R. (2004). On becoming a person. London, England: Constable.

Rudman, R. S. (2010). Performance planning and review. In Human resources management in New Zealand (5th ed., pp. 195-213). North Shore, NZ: Pearson.

Saleebey, D. (2006). The strengths perspective in social work practice (4th ed.). Boston: Pearson/Allyn \& Bacon.
Schein, E. H. (2010). Organizational culture and leadership (4th ed.). San Francisco, CA: Jossey-Bass.

Senge, P. M. (1997). The fifth discipline. Measuring Business Excellence, 1(3), 46-51. doi: http://dx.doi.org/10.1108/ eb025496

Scott, G. (2001). Public sector management in New Zealand: Lessons and challenges. Canberra, ACT: Centre for Law and Economics, Australian National University.

Taylor, F. W. (1967). The principles of scientific management. New York, NY: Norton.

The Modernising Child Youth and Family Panel. (2015). Expert panel final report: Investing in New Zealand's children and their families. Retrieved from http://www. msd.govt.nz/documents/about-msd-and-our-work/workprogrammes/investing-in-children/investing-in-childrenreport.pdf

Turnell, A., \& Edwards, S. (1997). Aspiring to partnership: The signs of safety approach to child protection. Child Abuse Review, 6(3), 179-190. doi: 10.1002/ (sici)1099-0852(199708)6:3<179::aid-car324>3.0.co;2-j

Wampold, B. E. (2001). The great psychotherapy debate: Models, methods, and findings. Mahwah, N.J.: L. Erlbaum Associates.

Wampold, B. E., \& Budge, S. L. (2012). The 2011 Leona Tyler Award Address: The relationship-and its relationship to the common and specific factors of psychotherapy. The Counseling Psychologist, 40(4), 601-623. doi: 10.1177/0011000011432709

Weaver, R. (1984). Ideas have consequences. Chicago, IL: University of Chicago Press.

Webster, M. (2013). Complexity approach to frontline social work management: Constructing an emergent team leadership design for a managerialist world. The situation in 2013. In J. Lawler \& T. Hafford-Letchfield (Eds.) Perspectives on management and leadership in social work (pp. 39-68). London, England: Whiting \& Birch.

Webster, M. (2014). A vision for social work leadership: Critical conceptual elements. In J. Duke, M. Henrickson \& L. Beddoe (Eds.), Protecting the Public - Enhancing the Profession. E tiaki ana i te Hapori - E manaaki ana i nga mahi (pp. 79-92). Wellington, New Zealand: Social Workers Registration Board. 